\title{
Scientific Advances of Milk Enrichment with Conjugated Linoleic Acid to Produce Anti-Cancer Milk
}

\author{
Mohammad-Hossein Biglu, ${ }^{1,}{ }^{*}$ Hossein Janmohammadi, ${ }^{2}$ and Lila Mirzapour ${ }^{3}$ \\ ${ }^{1}$ Department of Basic Sciences, Paramedical Faculty, Tabriz University of Medical Sciences, Tabriz, IR Iran \\ ${ }^{2}$ Department of Animal Science, Faculty of Agriculture, Tabriz University, Tabriz, IR Iran \\ ${ }^{3}$ Tabriz Health Services Management Research Center, Tabriz University of Medical Sciences, Tabriz, IR Iran \\ "Correspondent author: Dr. Mohammad-Hossien Biglu, Associate Professor, Department of Basic Sciences, Paramedical Faculty, Tabriz University of Medical Sciences, Tabriz, \\ IR Iran. E-mail: mh_biglu@yahoo.com
}

Received 2016 March 05; Revised 2016 May 30; Accepted 2017 January 14.

\begin{abstract}
Background: Conjugated linoleic acid (CLA) is an unsaturated fatty acid that after the discovery of its anti-cancerous properties numerous researches conducted to increase its concentration in the food products. The current study aimed to review researches in the field of milk enrichment with CLA to identify the main actors and highlight the achievements in the field; therefore, the effectiveness of these researches for producing anti-cancer milk was surveyed.

Methods: The journal of dairy science was selected for data extraction and related papers were identified via review of all published papers during years 2003 - 2013 and then were subjected into content analysis. Statistical analysis was done with the MEANS procedure of SAS software (Version 9.1).

Results: Among all collected papers, only 72 were eligible. Data analysis showed that the USA, Canada and France were the most productive countries in the field of milk enrichment with CLA. Surprisingly, Iran did not have any paper in this field in the journal of dairy science. The supplements that were added to the animal diets were enriched by linoleic or linolenic acids. Enhancing the milk cis-9, and trans-11 CLA content were the main objectives of researches. More than $70 \%$ of treatments led to the supply of the minimum amount of CLA to prevent cancer with serving milk twice a day.

Conclusions: Considerably, milk enrichment with CLA mostly has being attracted by developed countries. Enriching milk with CLA is a suitable scientific strategy to fight against cancer. It is important to increase researches in increasing trans-10, and cis- 12 CLA.
\end{abstract}

Keywords: Milk Enrichment, CLA, Anti-Cancer

\section{Introduction}

Cancer is a major risk for human health in today's world. As the international agency for research on cancer (IARC) has reported, in 2012, the global burden of cancer raised to 14 million new cases annually, a number expected to increase to 22 million per year in the next two decades. At the same time, cancer deaths were predicted to increase from 8.2 million cases to 13 million per year. In 2010, the total annual economic cost of cancer was estimated to rise about US\$ 1.16 trillion. Improving the diet is an effective method for prevention and controlling the cancer. Conjugated linoleic acid (CLA) is an unsaturated fatty acid that naturally exists in ruminant milk and meat products. CLA is produced during the rumen bacterial biohydrogenation process when linolenic acid is converted to stearic acid (1, $2)$. After the discovery of the anti-cancer properties of CLA in 1987 (3), numerous researches have examined the effects of fatty acid on cancer in animal models and cell culture. Many of the these researches were focused on cis-9, trans11 CLA and trans-10-, cis-12 CLA isomers and used a mixture or single form of these isomers. Based on the results of re- searches, CLA affects different stages of cancer; CLA inhibit proliferation and can induce apoptosis in breast, prostate, colon, gastric, liver, endometrial and osteosarcomas cancer cells and also prevent metastasis (4-11). Furthermore, a study on mice showed that at least 0.5\% CLA in the daily diet can reduce incidence of cancer (12). It can be concluded that CLA might be effective to control and prevent cancer.

The optimal intake of CLA for significant reduction of cancer risk in humans has not been established yet, but with the generalization of the studies on rats, a daily intake between 95 - 3500 mg of cis-9, trans-11 CLA is needed. According to the estimates, cis-9, trans-11 CLA intake among human population is about 15 to $1,500 \mathrm{mg}$ per day, which is much less than the amount that is necessary to reduce the risk of cancer (13).

Producing foods with origin of ruminant that have high CLA content is a suitable way to increase the amount of CLA intake, especially cis-9, trans-11 CLA without any need to change eating habits. Milk and dairy products consist 66 to 80 percent of human's CLA intake (14) and their con- 
sumption is more common in developed countries and seems to be increased in developing countries (15). Therefore, increasing the amount of CLA in milk can be a worthy way to control and prevent cancer. Nemours researches have been conducted to enhance milk CLA content. The majority of researches have changed animal diet composition to increase milk CLA content, because this method had a major effect on milk composition (16) and can be done by the farmers. Review of these researches could establish: the measures taken in milk enrichment with CLA, and the achievements that were accomplished in the field. Therefore, the present study aimed to do the content analysis on published papers in the field of enrichment of dairy cattle milk with CLA during years 2003 - 2013 in order to determine: 1- productive authors, organizations and countries; 2-the enriched levels, the amount and type of supplements that were added to dairy cattle rations for enrichment, and 3- the progresses of the researches to provide the optimal amount of needed CLA for controlling and preventing the cancer.

\section{Methods}

The current study is a meta-analysis, which used content analysis of papers. The Journal of dairy science was selected for data extraction. Based on journal citation reports, this journal has ranked second among agriculture, dairy and animal science journals in terms of impact factor (17). All volumes of the journal of dairy science, which were published during years 2003 - 2013 (11 volumes, 32 Numbers, 7 supplements) were reviewed. Only research papers went under content analysis. The results showed that the level of cis-9, trans-11 CLA, trans- 10-, cis-12 CLA isomers and total CLA were significantly $(\mathrm{P}<0.05)$ increased in dairy cattle milk through the manipulation of the animal diet. Statistical analysis was done with the MEANS procedure of SAS software (Version 9.1). To determine the amount of cis9, trans-11 CLA supplied by CLA-enriched milk in daily consumption of milk, the amount of cis-9, trans-11 CLA was calculated in $227 \mathrm{~mL}$ milk.

\section{Results}

A total of 72 papers met the inclusion criteria of the study. Figure 1 shows the number of papers in the field of milk enrichment with CLA during years 2003 - 2013. It illustrates that the number of papers published during the period of study increased and decreased narrowly; only in 2010 there was a significant decline so that the number of papers decreased from 7 papers in 2009 to 3 papers in 2010.

A total of 275 authors from 17 countries involved in publishing the papers in the field of milk enrichment with CLA.
Table 1 shows 10 productive countries and their organizations list. The USA was the leading country by contribution of about $51.43 \%$ of papers, followed by Canada and France. Surprisingly, Iran did not have any papers in the field and China was the only Asian country which contributed a paper. 10 prolific authors and their countries of origin are shown in Table 2. AbuGhazaleh A. A. was the most prolific author by participating in the production of $11.43 \%$ of papers, followed by D. E. Bauman and K. J. Shingfield (each with $10 \%$ of papers). As shown in Table 2, six prolific authors are from the USA. The number of participant organizations in publishing papers in this field was 78, of which 13 organizations involved in at least 3 papers (Table 3 ). Cornell University and National Institute for agricultural research, each sharing $11.43 \%$ of papers were leading organizations. The following was agriculture and agri-food Canada.

Based on extracted data, the total number of experiments was 75 which consisted of 171 dietary treatments that significantly increased the content of CLA in the dairy cattle milk. The Milk contain cis-9, trans-11 CLA was significantly enriched via 147 treatments and 61 treatments had significantly increased the milk trans-10-, cis-12 CLA content and the milk total CLA content was considerably increased by 71 treatments. Dietary supplements which were added to dairy cattle rations in order to raise the level of CLA in milk were included as oilseeds, oils (plant and animal oils), marine oils and feeds, forages, mixed dietary and other feed. Based on the result of the experiments the amount of total fatty acids of CLA-enriched milk was between 1.44\% - 5.21\%. CLA-enriched milk cis-9, trans-11 CLA, trans-10-, cis-12 CLA and total CLA content were reported as $0.06 \%-6.05 \%$ of FA, $0.0097-1.82 \%$ of FA and $0.35 \%-5.22 \%$ of FA, respectively.

Oil seeds: Table 4 shows oil seeds which were used to proliferate the milk content CLA and their amount in dairy cattle rations. Oilseeds include wild flaxseed, sunflower, cotton seeds, linseed, Solin (high linoleic flaxseed), corn, canola and rapeseed, which are rich in linoleic or linolenic acids. The total number of oilseed treatments was 43 . Flaxseed was used in $58.14 \%$ of treatments. Oilseeds proliferated the milk cis-9, trans-11 CLA content, about 0.33\% $-1.484 \%$ of FA, the content of trans- $10-$, cis-12 CLA about $0.01 \%$ $-0.2 \%$ of FA and the content of total CLA about $0.57 \%-1.9 \%$ of FA. The maximum level of cis-9, trans-11 CLA in milk was proliferated by $5.9 \%$ flaxseed; the maximum level of trans10 -, cis-12 CLA and total CLA were proliferated by $21 \%$ corn and $12.6 \%$ linseed, respectively.

Oils: At 50 dietary treatments, oils were added to the dairy cattle rations. The oils included synthetic CLA, unsaturated fatty acids, animal fat and plant oil seed (sunflower oil, flaxseed oil, cottonseed oil, corn oil, soybean oil, safflower oil, rapeseed oil). In the CLA-enriched milk by oils, range of cis-9, trans-11 CLA content were between $0.43 \%$ - 


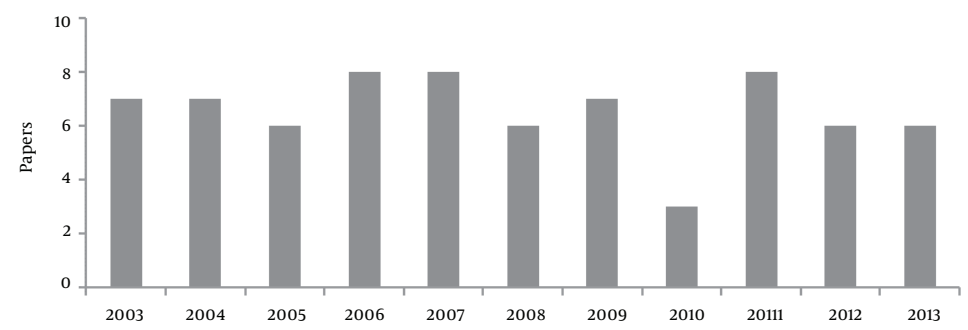

Figure 1. The Number of Papers in the Field of Milk Enrichment with CLA in Journal of Dairy Science (2003 - 2013)

Table 1. Ten Top Productive Countries in CLA and the Number of Their Involved Organizations in Publishing Papers in the Field of Milk Enrichment with in the Journal of Dairy Science $(2003-2013)$

\begin{tabular}{|c|c|c|c|c|}
\hline Rank & Country & Papers & Percentage & Organization No \\
\hline 1 & USA & 36 & 51.43 & 28 \\
\hline 2 & Canada & 14 & 20 & 13 \\
\hline 3 & France & 9 & 12.86 & 2 \\
\hline 4 & Finland & 7 & 10 & 2 \\
\hline 5 & Belgium & 3 & 4.29 & 6 \\
\hline 6 & Brazil & 3 & 4.29 & 4 \\
\hline 7 & China & 3 & 4.29 & 4 \\
\hline 8 & Germany & 3 & 4.29 & 1 \\
\hline 9 & England & 2 & 2.86 & 2 \\
\hline 10 & Netherlands & 2 & 2.86 & 5 \\
\hline
\end{tabular}

Table 2. Ten Top Prolific Authors in Field of Milk Enrichment with CLA and Their Country and Organization in the Journal of Dairy Science (2003 - 2013)

\begin{tabular}{lccccl}
\hline Rank & Authors & Papers & Percentage & Country & Organization \\
\hline $\mathbf{1}$ & A. A. AbuGhazaleh & 8 & 11.43 & USA & South Dakota State University; Southern Illinois University \\
\hline $\mathbf{2}$ & D. E. Bauman & 7 & 10 & USA & Cornell University \\
\hline $\mathbf{3}$ & K. J. Shingfield & 7 & 10 & England; Finland & The University of Reading; MTT Agrifood Research Finland \\
\hline $\mathbf{4}$ & A. R. Hippen & 6 & 8.57 & USA & South Dakota State University \\
\hline $\mathbf{5}$ & D. J. Schingoethe & 6 & 8.57 & USA & South Dakota State University \\
\hline $\mathbf{6}$ & H. V. Petit & 5 & 7.14 & Canada & Agriculture and Agri-Food Canada \\
\hline $\mathbf{7}$ & K. F. Kalscheur & 5 & 7.14 & USA & South Dakota State University \\
\hline $\mathbf{8}$ & Y. Chilliard & 5 & 7.14 & France & National Institute for Agricultural Research \\
\hline $\mathbf{9}$ & A. Ferlay & 4 & 5.71 & France & National Institute for Agricultural Research \\
\hline $\mathbf{1 0}$ & A. L. Lock & 4 & USA & Cornell University; University of Vermont \\
\hline
\end{tabular}

$4.12 \%$ of FA, range of trans- $10-$, cis-12 CLA and total CLA contents were $0.0038 \%-1.82 \%$ of FA and $0.6 \%-5.44 \%$ of FA, respectively. The maximum enriched level of cis-9, trans-11 CLA was resulted with $6 \%$ safflower. Using $3 \%$ linseed oil and rumen injection of $80 \mathrm{~g} / \mathrm{d}$ synthetic CLA, respectively, caused the maximum level of trans-10-, cis-12 CLA and total CLA in milk (Table 5).

Forages: The numbers of forage treatments for the milk enrichment with CLA were 11 including, silages of corn, red clover and grass, alfalfa hay and fresh forage. The treatments only significantly increased the milk cis-9, trans-11 CLA content. Enriched level of cis-9, trans-11 CLA was between $0.4 \%-109 \%$ of FA and $80 \%$ fresh grass had resulted maximum level (Table 6).

Agricultural byproducts: Distillers grains plus soluble, corn germ and mustard bran were agricultural byproducts which were used in 6 treatments for milk enrichment with CLA. CLA-enriched milk cis-9, trans-11 CLA content was about $0.6 \%-1.11 \%$ of FA. Also 10\% Distillers grain plus soluble led to the maximum level (Table 7).

Marine oils and feeds: Treatments of marine oils and feeds included 14 treatments of fish oil and algae. CLAenriched milk cis-9, trans-11 CLA content by marine was about $0.14 \%-6.05 \%$ of FA and content of trans-10-, cis-12 CLA 


\begin{tabular}{|c|c|c|c|c|}
\hline Rank & Organization & Papers & Percentage & Country \\
\hline 1 & Cornell University & 8 & 11.43 & USA \\
\hline 2 & INRA & 8 & 11.43 & France \\
\hline 3 & Agriculture and Agri-Food Canada & 7 & 10 & Canada \\
\hline 4 & South Dakota State University & 6 & 8.57 & USA \\
\hline 5 & University of Idaho & 5 & 7.14 & USA \\
\hline 6 & MTT Agrifood Research Finland & 5 & 7.14 & Finland \\
\hline 7 & University of Helsinki & 4 & 5.71 & Finland \\
\hline 8 & Southern Illinois University & 4 & 5.71 & USA \\
\hline 9 & University of Alberta & 4 & 5.71 & Canada \\
\hline 10 & Bioproducts Inc. & 3 & 4.28 & USA \\
\hline 11 & Ghent University & 3 & 4.28 & Belgium \\
\hline 12 & North Carolina A\&T State University & 3 & 4.28 & USA \\
\hline 13 & US Food and Drug Administration & 3 & 4.28 & USA \\
\hline
\end{tabular}

and total CLA were about $0.0097 \%-1.12 \%$ of FA and $0.6 \%$ - $4.18 \%$ of FA, respectively. Injection of $16 \mathrm{~g} / \mathrm{d}$ fish oil into the rumen increased cis-9, trans-11 CLA content at maximum level. The highest levels of trans-10-, cis-12 CLA and total CLA were achieved as a result of adding $0.97 \%$ fish oil and adding $1 \%$ algae to dairy cattle rations (Table 8 ).

Mixed diets: Based on the data analysis, in 28 treatments combinations of oilseeds, oils, oil seeds and oil were examined. CLA-enriched milk cis-9, trans-11 CLA content ranged from $0.52 \%-4.47 \%$ of FA and the content of trans10 -, cis-12 CLA was about $0.2 \%-0.28 \%$ of FA. Mixed diets increased the content of total CLA for levels $1.12 \%-3.47 \%$ of FA. Adding mixture of fish oil and algae, soybean oil and synthetic CLA, fish oil and sunflower oil to dairy cattle rations respectively, led to the highest levels of cis-9, trans-11 CLA, trans-10-, cis-12 CLA and total CLA in milk (Table 9).

Canola meal and concentrate were other dietary supplements which were added to dairy cattle rations for enriching milk with CLA. Canola meal increased total CLA levels to $1.17 \%$ of FA. However, concentrate increased level of cis-9, trans-11 CLA to 1.13\% of FA (Table 10).

\subsection{Amount of CLA in One Serving CLA-Enriched Dairy Cattle Milk}

Data analysis showed $227 \mathrm{~mL}$ (one serving) of CLAenriched milk can provide 10 - $380 \mathrm{mg}$ cis-9, trans-11 CLA. Among all treatments, 52 treatments led to supply of 95 $380 \mathrm{mg}, 58$ treatments let to supply of 48 - $92 \mathrm{mg}$ and 30 treatments led to supply of 10 - $48 \mathrm{mg}$ cis-9, trans-11 CLA in 227 mL CLA-enriched milk. (Tables 4 -10)

\section{Discussion}

According to the findings, papers production had no clear trend during the period of study. The number of pa- pers in 2010 was lower than other years which increased again in 2011. The majority of researches in the field of dairy cattle milk enrichment with the CLA were done by developed countries especially the USA during the period of study. Reviewing selected papers showed that $47.46 \%$ of papers which were published in years 2003-2009 were those of the USA. By the end of 2009, the USA had an annual average of 4.12 papers and the average number of papers from 2010 to 2013 were 2.28 annually. Most productive countries like Finland and Belgium in term of paper publication were mostly active in 2011. Hence it can be concluded that the performance of the USA and other chief productive countries could be the main reason of the falling number of papers in 2010 and rising number of papers in 2011.

Production of animal products with high nutritional value is economically very expensive and depends on local and seasonal conditions, and the availability of resources. Usage of dietary supplements like plant oils or fish oil for producing high nutritional value foods, due to its cost may discourage farmers from this action (15). The findings of this study showed that a large number of productive countries were the developed countries, which have high incomes (18). According to statistics which was provided by FAO, the USA ranks second in terms of milk production and per capita milk consumption in the USA is higher than usual (150 kg/capita/year), also rank of India and Pakistan in terms of milk production are first and fifth, respectively. Milk consumption per capita is higher than usual in Pakistan (19, 20). However, India and Pakistan did not have any paper in the field of milk enrichment with CLA, which confirms that the economical power of developing countries as well as China (18) is an important factor to carry out such researches in these countries. On the other hand, findings of this current study indicated that 28 from 78 organiza- 
Table 4. The Oilseeds Used in Milk Enrichment with CLA, Milk CLA Content (\% of Total Fatty Acids) and Content of cis-9, trans-11 CLA (mg) in 227 mL CLA-Enriched Milk

\begin{tabular}{|c|c|c|c|c|c|c|}
\hline Dietary Supplement & $\%$ of DM & Cis-9, trans-11 CLA & Trans-10-, cis-12 CLA & Total CLA & Total Fatty Acid & Cis-9, trans-11 CLA, mg/227 mL \\
\hline \multirow[t]{3}{*}{ Camelina } & 2.9 & 0.927 & $\cdot$ & 1.026 & 2.51 & 53 \\
\hline & 5.9 & 1.484 & . & 1.737 & 1.44 & 50 \\
\hline & 2.9 & 1.02 & - & 1.33 & 3.67 & 85 \\
\hline Cottonseed & 9.44 & 0.66 & - & - & 3.67 & 55 \\
\hline \multirow[t]{2}{*}{ Sunflower seed } & 8.7 & 1.43 & - & - & 3.37 & 110 \\
\hline & 10.55 & 0.97 & - & - & 3 & 66 \\
\hline \multirow{27}{*}{ Flaxseed } & 8.3 & 0.73 & - & 0.97 & 3.44 & 57 \\
\hline & 8.3 & 1.46 & - & 1.83 & 2.72 & 91 \\
\hline & 12.6 & - & - & 1.4 & - & - \\
\hline & 12.6 & - & - & 1.4 & - & - \\
\hline & 12.6 & - & . & 1.9 & - & - \\
\hline & 11.8 & 0.77 & - & - & 4.45 & 80 \\
\hline & 9 & 0.98 & . & . & 3.69 & 80 \\
\hline & 6.5 & 0.87 & 0.12 & 1 & 3.99 & 79 \\
\hline & 9.3 & 1.24 & - & - & 4.24 & 120 \\
\hline & 9.32 & 0.68 & $\cdot$ & - & 3.3 & 51 \\
\hline & 6.5 & 0.56 & - & 0.57 & 4.3 & 55 \\
\hline & 9.9 & 0.35 & - & 0.35 & 4.75 & 38 \\
\hline & 5 & 0.915 & - & 1.08 & 3.5 & 73 \\
\hline & 10 & 1.64 & - & 1.89 & 3.5 & 130 \\
\hline & 15 & 1.122 & . & 1.28 & 2.91 & 74 \\
\hline & 5 & 0.71 & 0.015 & 0.81 & 3.07 & 50 \\
\hline & 10 & 0.77 & 0.02 & 0.96 & 2.71 & 47 \\
\hline & 15 & 0.92 & 0.01 & 1.05 & 3.12 & 65 \\
\hline & 8.3 & 0.91 & . & . & 4.31 & 89 \\
\hline & 11.83 & 1.19 & - & - & 4.27 & 115 \\
\hline & 8.3 & 0.9 & - & - & 4.3 & 88 \\
\hline & 7.9 & 0.43 & - & - & 4.28 & 42 \\
\hline & 7.9 & 0.53 & . & - & 4.36 & 52 \\
\hline & 9 & 0.8 & . & . & 3.7 & 67 \\
\hline & 9 & 0.9 & - & - & 2.89 & 59 \\
\hline & 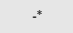 & 0.91 & . & - & 3.35 & 70 \\
\hline &.$^{*}$ & 0.9 & 0.017 & 1.2 & 3.35 & 64 \\
\hline Solin & 10 & 1.3 & - & - & 3.86 & 114 \\
\hline \multirow[t]{5}{*}{ Corn } & 30.8 & 0.39 & . & 0.41 & 3.79 & 34 \\
\hline & 20.9 & 0.33 & . & 0.35 & 4.07 & 30 \\
\hline & 7 & 0.86 & 0.12 & - & 3.72 & 70 \\
\hline & 14 & 0.97 & 0.13 & - & 3.78 & 80 \\
\hline & 21 & 1.13 & 0.2 & - & 3.3 & 85 \\
\hline \multirow[t]{3}{*}{ Canola seed } & 9.32 & 0.61 & . & . & 3.1 & 43 \\
\hline & 8.13 & 0.61 & & 0.84 & 3.34 & 45 \\
\hline & 8.13 & 0.56 & - & 0.79 & 2.94 & 23 \\
\hline \multirow[t]{5}{*}{ Rapeseed } & 6.9 & 1 & - & - & 4.18 & 95 \\
\hline &.$^{*}$ & 0.84 & - & - & & - \\
\hline & $*^{*}$ & 0.9 & - & - & & - \\
\hline &.$^{*}$ & 0.744 & . & . & & - \\
\hline &.$^{*}$ & 0.89 & . & . & & . \\
\hline
\end{tabular}

tions, and $50 \%$ of main productive organizations are located in the USA, also 6 prolific authors are from this country; hence $52.77 \%$ of papers belonged to the USA. No paper was published from Iran. It could be because milk produc- tion by Iran is less than the amount of population's need and the per capita consumption of milk is medium or less than normal amount (19); therefore, the amount of milk production is considered more important than the quality 
Table 6. The Forages Used in Milk Enrichment with CLA, milk CLA Content (\% of Total Fatty Acids) and Content of cis-9, trans-11 CLA (mg) in $227 \mathrm{~mL}$ CLA-Enriched Milk

\begin{tabular}{|c|c|c|c|c|c|c|}
\hline Dietary Supplement & $\%$ of DM & Cis-9, trans-11 CLA & Trans-10-, cis-12 CLA & Total CLA & Total Fatty Acid & Cis-9, trans-11 CLA, mg/227 mL \\
\hline \multirow[t]{2}{*}{ Corn silage } & 50.1 & 1.37 & - & - & 2.45 & 20 \\
\hline & 77.5 & 1.61 & - & - & 4.47 & 160 \\
\hline red clover silage & 50 & 0.4 & - & - & 3.78 & 34 \\
\hline Grass silage & 50 & 0.45 & - & - & 3.68 & 38 \\
\hline Alfalfa hay & 49.2 & 0.69 & - & - & 3.13 & 50 \\
\hline \multirow[t]{6}{*}{ Fresh forage } & 50 & 1.57 & - & - & 3.42 & 120 \\
\hline & 65 & 1.61 & - & - & 3.91 & 143 \\
\hline & 80 & 1.9 & - & - & 3.71 & 160 \\
\hline & 30 & 0.54 & - & - & 4.39 & 50 \\
\hline & 60 & 1.21 & - & - & 4.09 & 110 \\
\hline & 100 & 1.65 & - & - & 4.01 & 150 \\
\hline
\end{tabular}

Table 7. Agricultural Byproducts Used in Milk Enrichment with CLA, Milk CLA Content (\% of Total Fatty Acids) and Content of cis-9, trans-11 CLA (mg) in 227 mL CLA-Enriched Milk

\begin{tabular}{|c|c|c|c|c|c|c|}
\hline Dietary Supplement & \% of DM & Cis-9, trans-11 CLA & Trans- 10-, cis-12 CLA & Total CLA & Total Fatty Acid & Cis-9, trans-11 CLA $(\mathrm{mg} / 227 \mathrm{ml})$ \\
\hline \multirow[t]{4}{*}{ Distillers grain plus solubles } & 5 & 0.6 & - & - & 3.35 & 64 \\
\hline & 10 & 0.77 & - & - & 3.33 & 60 \\
\hline & 15 & 0.83 & - & - & 3.24 & 60 \\
\hline & 10 & 1.11 & 0.13 & 1.24 & 3.33 & 10 \\
\hline Corn germ & 3.64 & 0.92 & - & - & 3.55 & 70 \\
\hline Mustard bran & 7.9 & - & 0.009 & - & - & - \\
\hline
\end{tabular}

Table 8. The Marine Oils and Feeds Used in Milk Enrichment with CLA, Milk CLA Content (\% of Total Fatty Acids) and Content of cis-9, trans-11 CLA (mg) in 227 mL CLA-Enriched Milk

\begin{tabular}{|c|c|c|c|c|c|c|}
\hline Dietary Supplement & $\%$ of DM & Cis-9, trans-11 CLA & Trans-10-, cis-12 CLA & Total CLA & Total Fatty Acid & Cis-9, trans-11 CLA, mg/227 mL \\
\hline \multirow[t]{6}{*}{ Fish oil } & $16, \mathrm{~g} / \mathrm{d}^{\mathrm{a}}$ & 6.05 & - & - & 2.76 & 380 \\
\hline & $16, \mathrm{~g} / \mathrm{d}^{\mathrm{a}}$ & 0.49 & - & - & 3.56 & 40 \\
\hline & 0.5 & 0.14 & 1.04 & - & 3.4 & 10 \\
\hline & 2.14 & 3.41 & - & - & 3.17 & 230 \\
\hline & 1.1 & 0.45 & 0.154 & 0.6 & 3.56 & 36 \\
\hline & 0.97 & - & 1.12 & - & - & - \\
\hline \multirow[t]{5}{*}{ algae } & 8.5 & 1 & - & - & 3.22 & 10 \\
\hline & 2.14 & 4.21 & - & - & 3.43 & 330 \\
\hline & 11 & 1.36 & 0.0097 & - & 3.16 & 98 \\
\hline & 1 & - & - & 3.59 & - & - \\
\hline & 1 & - & - & 4.18 & - & - \\
\hline
\end{tabular}

${ }^{\mathrm{a}}$ Has been injected into the rumen.

of milk in Iran.

Based on the review study by TILAK R. et al. pasture grass, plant oil seeds and oils, marine oils and feed and animal fat that are rich in linoleic or linolenic acids, or are 
Table 9. The Mixed Diets Used in Milk Enrichment with CLA, Milk CLA Content (\% of total Fatty Acids) and Content of cis-9, trans-11 CLA (mg) in 227 mL CLA-Enriched Milk

\begin{tabular}{|c|c|c|c|c|c|c|}
\hline Dietary Supplement & $\%$ of DM & Cis-9, trans-11 CLA & Trans-10-, cis-12 CLA & Total CLA & Total Fatty Acid & Cis-9, trans-11 CLA, g/227 mL \\
\hline Flaxseed + flax oil & - & 0.53 & - & - & 2.3 & 28 \\
\hline Flaxseed + buck wheat & . & 1.27 & . & 1.33 & 3.53 & 100 \\
\hline Corn + pasture & 6.66 & - & - & 1.12 & - & . \\
\hline PUFA + pasture & 15.83 & . & . & 1.91 & & - \\
\hline PUFA + Ca salt of palm fatty acids & 1.6 & 0.52 & - & - & 3.22 & 40 \\
\hline Flax oil + DHA & . & 1.45 & - & 1.45 & 3.27 & 110 \\
\hline Flax oil + soybean oil & . & 1.81 & . & . & 3.3 & 140 \\
\hline \multirow[t]{2}{*}{ Soybean oil + CLA } & . & 0.98 & 0.1 & 1.27 & 2.17 & 50 \\
\hline & - & 0.79 & 0.28 & 1.41 & 2.22 & 40 \\
\hline \multirow[t]{8}{*}{ Fish oil + sunflower oil } & . & 1.04 & 0.07 & - & 2.81 & 70 \\
\hline & $\cdot$ & 1.7 & 0.12 & $\cdot$ & 2.66 & 100 \\
\hline & - & 4.46 & - & . & 3.54 & 360 \\
\hline & - & 3.04 & 0.075 & 3.47 & 2.9 & 200 \\
\hline & - & 1.64 & - & . & 3.5 & 130 \\
\hline & . & 0.84 & . & . & 2.51 & 48 \\
\hline & - & 1.53 & - & - & 2.95 & 100 \\
\hline & & - & & & - & - \\
\hline \multirow[t]{3}{*}{ Fish oil + soy beans } & . & 1.17 & 0.03 & . & 3.81 & 100 \\
\hline & - & 1.03 & 0.03 & - & 3.8 & 90 \\
\hline & . & 1.19 & 0.03 & - & 4.03 & 110 \\
\hline Fish oil + soybean oil & . & 1.16 & 0.04 & . & 3.17 & 80 \\
\hline Fish oil + stearic acid & - & 0.7 & 0.02 & . & 3.14 & 50 \\
\hline \multirow[t]{2}{*}{ Fish oil + algae } & - & 3.69 & - & - & 3.49 & 290 \\
\hline & . & 4.47 & - & - & 3.74 & 360 \\
\hline Fish oil + flaxseed & - & 1.06 & 0.03 & - & 3.08 & 74 \\
\hline \multirow[t]{3}{*}{ Fish oil + Ca salt of palm fatty acids } & - & 1.2 & 0.07 & 1.27 & 3.32 & 90 \\
\hline & $\cdot$ & 0.7 & $\cdot$ & $\cdot$ & 3.76 & 60 \\
\hline & - & 1.04 & . & . & 3.61 & 85 \\
\hline Fish oil + Ca salt of palm fatty acids + soybeans & $\cdot$ & 1.36 & 0.08 & 1.44 & 3.33 & 100 \\
\hline Fish oil + Ca salt of palm fatty acids + soybean oil & - & 1.74 & 0.08 & 1.82 & 2.89 & 110 \\
\hline
\end{tabular}

Table 10. Other Dietary Supplements Used in Milk Enrichment with CLA, Milk CLA Content (\% of Total Fatty Acids) and Content of cis-9, trans-11 CLA (mg) in 227 mL CLA-Enriched Milk

\begin{tabular}{|c|c|c|c|c|c|c|}
\hline Dietary Supplement & \% of DM & Cis-9, trans-11 CLA & Trans-10-, cis-12 CLA & Total CLA & Total Fatty Acid & Cis-9, trans-11 CLA, mg/227 mL \\
\hline Canola meal & 13 & - & - & 1.17 & - & - \\
\hline Concentrate & 2.55 & 1.13 & - & - & 3.81 & 100 \\
\hline
\end{tabular}

able to change the rumen biohydrogenation process, are effective substances to enhance the content of CLA in milk (21). The results of this study are in accordance with their findings and indicated that dietary supplements such as sunflower, soybean, flaxseed and their oils which are rich in linoleic or linolenic acids, and marine oils which are rich in long-chain PUFA could proliferate the milk CLA content. Increasing vaccenic acid production in the rumen is a key way to raise the milk CLA content, so supplementation of dairy cattle rations with diets which are rich in linoleic, linolenic acids or diets containing marine oilrich in long-chain PUFA and by changing rumen biohydro- genation process could inhibit vaccenic acid reduction to stearic acid-increase the content of CLA in milk (22).

Given that cis-9, trans-11 CLA is a predominant CLA isomer in ruminant milk and meat that has health benefits in humans, increasing the content of this isomer in meat and milk is the main objective in the field of enrichment of ruminant products with $\operatorname{CLA}(23,24)$. The results of this study indicated that $93.96 \%$ of treatments had significantly increased the milk cis-9, trans-11 CLA content. This could represent that increasing this isomer is the purpose of the most researches conducted in this field.

The recommended amount of milk for daily consump- 
tion is two glasses. Based on the results of this study, more than $70 \%$ of treatments provided the minimum amount of cis-9, trans-11 CLA needed for preventing and reducing the cancer risk in humans with two glasses of milk a day.

Based on the report of Larsson et al. long-term consumption of high-fat dairy products and a high CLA intake could reduce the risk of colon cancer (25). Although the research on milk enrichment with CLA could not provide the maximum amount of CLA which is necessary for reducing cancer risk, but according to success of researches on providing the minimum amount, it can be concluded that the milk enrichment with CLA is an effective action against cancer.

Although milk enrichment with CLA is expensive, but due to the high rate of cancer in Iran $(26,27)$, it would be more reasonable and cost-beneficial to produce the enriched milk with CLA acceptably in the countries like Iran.

Results of our study revealed that studies related to the milk trans-10-, cis-12 CLA content were not considered appropriately. Since this isomer, either directly or indirectly through reducing obesity and as a result, obesity related cancers is effective in reducing cancer risks $(7,28,29)$. further research to consider this isomer in milk enrichment is recommended.

\section{Footnotes}

Authors' Contribution: Mohammad-Hossein Biglu developed the original idea and the protocol, and administered the study. Hossein Janmohammadi helped analyzing data and reviewing manuscript. Lila Mirzapour gathered data, analyzed and prepared the first draft of manuscript.

Conflict of Interest: The authors declare that there is no conflict of interests.

Financial Disclosure: Non declared.

\section{References}

1. Stewart BW, Wild CP. World Cancer Report 2014. Lyon, France: International Agency for Research on Cancer; 2014.

2. Chin SF, Liu W, Storkson JM, Ha YL, Pariza MW. Dietary sources of conjugated dienoic isomers of linoleic acid, a newly recognized class of anticarcinogens. J Food Compos Analysis. 1992;5(3):185-97. doi: 10.1016/0889-1575(92)90037-k.

3. Kepler CR, Hirons KP, McNeill JJ, Tove SB. Intermediates and products of the biohydrogenation of linoleic acid by Butyrinvibrio fibrisolvens. J Biol Chem. 1966;241(6):1350-4. [PubMed: 5936712].

4. Ha YL, Grimm NK, Pariza MW. Anticarcinogens from fried ground beef: heat-altered derivatives of linoleic acid. Carcinogenesis. 1987;8(12):1881-7. [PubMed: 3119246].

5. Song HJ, Sneddon AA, Heys SD, Wahle KW. Regulation of fatty acid synthase (FAS) and apoptosis in estrogen-receptor positive and negative breast cancer cells by conjugated linoleic acids. Prostaglandins Leukot Essent Fatty Acids. 2012;87(6):197-203. doi: 10.1016/j.plefa.2012.09.002. [PubMed: 23142364].
6. Ochoa JJ, Farquharson AJ, Grant I, Moffat LE, Heys SD, Wahle KW. Conjugated linoleic acids (CLAs) decrease prostate cancer cell proliferation: different molecular mechanisms for cis-9, trans-11 and trans-10, cis-12 isomers. Carcinogenesis. 2004;25(7):1185-91. doi: 10.1093/carcin/bgh116. [PubMed: 14976130].

7. Kim KJ, Lee J, Park Y, Lee SH. ATF3 Mediates Anti-Cancer Activity of Trans-10, cis-12-Conjugated Linoleic Acid in Human Colon Cancer Cells. Biomol Ther (Seoul). 2015;23(2):134-40. doi: 10.4062/biomolther.2014.107. [PubMed: 25767681].

8. Bae WK, Park MS, Lee JH, Hwang JE, Shim HJ, Cho SH, et al. Docetaxel-loaded thermoresponsive conjugated linoleic acidincorporated poloxamer hydrogel for the suppression of peritoneal metastasis of gastric cancer. Biomaterials. 2013;34(4):1433-41. doi: 10.1016/j.biomaterials.2012.10.077. [PubMed: 23174142].

9. Wang J, Liu X, Zhang X, Liu J, Ye S, Xiao S, et al. Induction of apoptosis by c9, t11-CLA in human endometrial cancer RL 95-2 cells via ERalpha-mediated pathway. Chem Phys Lipids. 2013;175-176:27-32. doi: 10.1016/j.chemphyslip.2013.07.009. [PubMed: 23954748].

10. Beppu F, Hosokawa M, Tanaka L, Kohno H, Tanaka T, Miyashita K. Potent inhibitory effect of trans9, trans11 isomer of conjugated linoleic acid on the growth of human colon cancer cells. $J$ Nutr Biochem. 2006;17(12):830-6. doi: 10.1016/j.jnutbio.2006.01.007. [PubMed: 16563722].

11. Chujo H, Yamasaki M, Nou S, Koyanagi N, Tachibana H, Yamada K. Effect of conjugated linoleic acid isomers on growth factorinduced proliferation of human breast cancer cells. Cancer Lett. 2003;202(1):81-7. [PubMed: 14643029].

12. Wong J, Kim Y, Park Y, Lee SH, Baek SJ, Park Y. Isomer specificity of conjugated linoleic acid on suppression of osteosarcomas. J Nat Sci. 2015;1(4):67.

13. Ip C, Chin SF, Scimeca JA, Pariza MW. Mammary cancer prevention by conjugated dienoic derivative of linoleic acid. Cancer Res. 1991;51(22):6118-24. [PubMed: 1933874].

14. Collomb M, Schmid A, Sieber R, Wechsler D, Ryhänen EL. Conjugated linoleic acids in milk fat: Variation and physiological effects. Int Dair J. 2006;16(11):1347-61.

15. Shingfield KJ, Wallace RJ. Synthesis of conjugated linoleic acid in ruminants and humans. London: The Royal Society of Chemistry; 2015.

16. Muehlhoff E, Bennett A, MacMahon D. Milk and dairy products in human nutrition Rome: Food and Agriculture Organization of the United Nations; 2013. Available from: http://www.fao.org/docrep/ 018/i3396e/i3396e.pdf.

17. Cortes C, da Silva-Kazama DC, Kazama R, Gagnon N, Benchaar C, Santos GT, et al. Milk composition, milk fatty acid profile, digestion, and ruminal fermentation in dairy cows fed whole flaxseed and calcium salts of flaxseed oil. J Dairy Sci. 2010;93(7):3146-57. doi: 10.3168/jds.2009-2905. [PubMed: 20630232].

18. InCites . Journal Citation Reports New York: Thomson Reuters; 2015 Available from: https://error.incites.thomsonreuters.com/error/ Error?DestApp=IC2JCR\&Alias=IC2\&Domain=.thomsonreuters. com $\&$ Src $=$ IP $\&$ Params $=$ DestApp\%3DIC2JCR $\&$ RouterURL $=$ https $\% 3 \mathrm{~A} \% 2 \mathrm{~F} \% 2 \mathrm{Flogin}$.incites.thomsonreuters.com\%2F\&Error= IPError.

19. The World Bank. Dairy. Washington, D.C.: The World Bank; 2015.

20. FAO . Dairy production and products 2015. Available from: http://www.fao.org/agriculture/dairy-gateway/milk-and-milkproducts/en/\#.VZnjMvmqqkp.

21. FAO . Dairy production 2015. Available from: http://faostat3.fao.org/ browse/Q/QL/E.

22. Dhiman TR, Nam SH, Ure AL. Factors affecting conjugated linoleic acid content in milk and meat. Crit Rev Food Sci Nutr. 2005;45(6):463-82. doi: 10.1080/10408390591034463. [PubMed:16183568].

23. Lock AL, Bauman DE. Modifying milk fat composition of dairy cows to enhance fatty acids beneficial to human health. Lipids. 2004;39(12):1197-206. [PubMed: 15736916]. 
24. AbuGhazaleh AA, Schingoethe DJ, Hippen AR, Kalscheur KF. Milk conjugated linoleic acid response to fish oil supplementation of diets differing in fatty acid profiles. J Dairy Sci. 2003;86(3):944-53. doi: 10.3168/jds.S0022-0302(03)73677-7. [PubMed: 12703631]

25. Huth PJ, DiRienzo DB, Miller GD. Major scientific advances with dairy foods in nutrition and health. J Dairy Sci. 2006;89(4):1207-21. doi: 10.3168/jds.S0022-0302(06)72190-7. [PubMed: 16537954].

26. Biglu MH. Breast Cancer in Iran: the Trend of Iranian Researchers' Studies in MEDLINE Database. Basic Clin Cancer Res. 2014;6(1):22-32.

27. Biglu MH, Shahkhodabandeh S, Asadi M. Publications on Breast Neo- plasms in Medline: AComparison between Iran and Other Middle East Countries. J Health Adm. 2012;9(1):119.

28. Yamasaki M, Nagatomo T, Matsuyama T, Ikeho Y, Kato E, Nishiyama $\mathrm{K}$, et al. Conjugated linoleic acids inhibit hypoxia inducible factor1alpha stabilization under hypoxic condition in human hepatocellular carcinoma cells. J Oleo Sci. 2012;61(9):491-6. [PubMed: 22975783].

29. Bhattacharya A, Banu J, Rahman M, Causey J, Fernandes G. Biological effects of conjugated linoleic acids in health and disease. $J$ Nutr Biochem. 2006;17(12):789-810. doi:10.1016/j.jnutbio.2006.02.009. [PubMed: 16650752]. 
Table 5. The Oils Used in Milk Enrichment with CLA, Milk CLA Content (\% of Total Fatty Acids) and Content of cis-9, trans-11 CLA (mg) in 227 mL CLA-Enriched Milk

\begin{tabular}{|c|c|c|c|c|c|c|}
\hline Dietary Supplement & $\%$ of DM & Cis-9, trans-11 CLA & Trans-10-, cis-12 CLA & Total CLA & Total Fatty Acid & Cis-9, trans-11 CLA), mg/227 mL \\
\hline \multirow[t]{8}{*}{ CLA synthetic } & 1.13 & & 0.09 & 0.6 & - & - \\
\hline & 1.22 & . & 0.08 & 1.08 & . & . \\
\hline & 3.75 & . & 0.25 & 2.69 & - & . \\
\hline & 0.43 & & 0.028 & 0.83 & - & . \\
\hline & 1 & 0.48 & 0.05 & 0.72 & 2.62 & 30 \\
\hline & 1 & 0.44 & 0.17 & 0.9 & 2.62 & 30 \\
\hline & 0.75 & 1.72 & 0.08 & 2.28 & 2.14 & 84 \\
\hline & 2.5 & 1.07 & 0.28 & . & 3.86 & 83 \\
\hline \multirow[t]{11}{*}{ CLA synthetic ${ }^{\mathrm{a}}$} & 20 & . & . & 2.56 & - & . \\
\hline & 40 & - & - & 2.98 & - & - \\
\hline & 80 & . & . & 5.44 & - & . \\
\hline & 150 & 1.77 & 0.85 & - & 1.78 & 72 \\
\hline & 4 & . & 0.06 & . & . & . \\
\hline & 6 & . & 0.1 & . & . & . \\
\hline & 4 & 0.66 & 0.19 & . & 1.95 & 30 \\
\hline & 10 & 0.83 & 0.08 & . & 2.37 & 45 \\
\hline & 10 & 0.8 & 0.09 & . & 2.34 & 40 \\
\hline & 5 & - & 0.18 & . & . & . \\
\hline & 100 & 0.83 & 0.02 & 2.59 & 2.16 & 40 \\
\hline DHA & 0.5 & 1.04 & 0.51 & . & 3.24 & 76 \\
\hline LA & 2.7 & 1.43 & . & . & 3.13 & 100 \\
\hline LA+DHA & . & 2.67 & . & . & 3.01 & 180 \\
\hline tallow & 1.67 & 0.71 & - & - & 3.56 & 60 \\
\hline \multirow[t]{7}{*}{ Sunflower oil } & 1.5 & 1.46 & . & 1.9 & - & . \\
\hline & 3 & 1.85 & . & 2.36 & 3.63 & 150 \\
\hline & 4.5 & 3.28 & - & 3.87 & 3.39 & 250 \\
\hline & 2.9 & 0.64 & . & 0.83 & 3.64 & . \\
\hline & 1.99 & . & . & 1.11 & . & . \\
\hline & 2.94 & . & . & 0.976 & . & . \\
\hline & 4.18 & . & 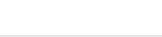 & 1.95 & . & . \\
\hline \multirow[t]{13}{*}{ Flaxseed oil } & 3 & 1.34 & 1.82 & . & 3.45 & 100 \\
\hline & 3 & 2.54 & . & . & 2.22 & 130 \\
\hline & 4 & 1.6 & . & . & 3.21 & 120 \\
\hline & 2.57 & 1.18 & . & . & 3.44 & 92 \\
\hline & 5.12 & 1.39 & . & . & 3.35 & 100 \\
\hline & 7.67 & 1.65 & . & . & 3.27 & 120 \\
\hline & 2 & 1.54 & - & . & 3.59 & 130 \\
\hline & 1.9 & 0.67 & . & . & 1.83 & 28 \\
\hline & 5 & 2.67 & 0.08 & . & 3.07 & 190 \\
\hline & 1.88 & 0.876 & - & 0.95 & 5.21 & 104 \\
\hline & 2.96 & 1.73 & - & 1.82 & 4.52 & 177 \\
\hline & 4.44 & 2.09 & . & 2.22 & 4.68 & 22 \\
\hline & 3.3 & 0.43 & - & 0.45 & 4.67 & 46 \\
\hline Camelina oil & 2.9 & 0.567 & 0.004 & 0.79 & 3.93 & 51 \\
\hline Ca salt of palm fatty acids & 1.6 & 0.44 & . & . & 3.34 & 30 \\
\hline Cottonseed oil & 2 & 0.6 & . & . & 3.34 & 46 \\
\hline \multirow[t]{3}{*}{ Corn oil } & 2 & 0.69 & - & . & 3.18 & 50 \\
\hline & 1.5 & 0.89 & - & . & 3.28 & 66 \\
\hline & 5 & 3.68 & 0.09 & . & 3.05 & 250 \\
\hline Soybean oil & 2 & 1.02 & . & . & 3.05 & 70 \\
\hline
\end{tabular}




\begin{tabular}{|c|c|c|c|c|c|c|}
\hline & 4 & 2.39 & . & . & 3.26 & 180 \\
\hline & 1.7 & 0.65 & 0.009 & 0.75 & 3.59 & 53 \\
\hline & 3.4 & 0.96 & 0.016 & 1.09 & 3.14 & 70 \\
\hline & 5 & 0.984 & 0.11 & 1.23 & 2.73 & 60 \\
\hline PUFA & 2.5 & 0.63 & 0.03 & . & 2.43 & 35 \\
\hline \multirow[t]{3}{*}{ Safflower oil } & 6 & 3.36 & 0.05 & . & 2.83 & 220 \\
\hline & 6 & 4.12 & 0.04 & & 2.97 & 280 \\
\hline & 5 & 4.09 & 0.12 & & 2.83 & 260 \\
\hline Rapeseed oil & 2.9 & 0.56 & 0.0038 & 0.77 & 3.86 & 50 \\
\hline
\end{tabular}

${ }^{\mathrm{a}}$ Has been injected into the rumen. 